\title{
A Flag-Based Algorithm and Associated Neutron Interrogation System for the Detection of Explosives in Sea-Land Cargo Containers
}

\author{
A.L. Lehnert ${ }^{a},{ }^{\star}$, K.J. Kearfott ${ }^{a}$ \\ a University of Michigan, 2355 Bonisteel Blvd, Ann Arbor, MI, USA
}

\section{ABSTRACT}

Recent efforts in the simulation of sea-land cargo containers in active neutron interrogation scenarios resulted in the identification of several flags indicating the presence of conventional explosives. These flags, defined by specific mathematical manipulations of the neutron and photon spectra, have been combined into a detection algorithm for screening cargo containers at international borders and seaports. The detection algorithm's steps include classifying the cargo type, identifying containers filled with explosives, triggering in the presence of concealed explosives, and minimizing the number of false positives due to cargo heterogeneity. The algorithm has been implemented in a system that includes both neutron and photon detectors. This system will take about ten minutes to scan a container and cost approximately $\$ 1 \mathrm{M}$ to construct. Dose calculations resulted in estimates of less than $0.5 \mathrm{mSv}$ for a person hidden in the container, and an operator annual dose of less than $0.9 \mathrm{mSv}$.

\section{KEYWORDS}

* Corresponding author: A.L Lehnert, currently at Univ. Washington. Tel.: +1 425 239 9067. Fax: +1 206543 8356. E-mail address: alehnert@uw.edu. Permanent address: $419120^{\text {th }}$ St. SE, Everett, WA 98208, USA 
Fast neutron interrogation, explosives detection, cargo containers

\section{Introduction}

\subsection{Explosives detection at sea ports}

The United States government requires that $100 \%$ of cargo containers originating outside the U.S. and unloaded at U.S. ports be screened to identify high-risk container (Safe Port Act, 2006). Smuggled conventional explosives are

of particular concern and are generally detected by either searching for chemical traces left by the explosives, or scanning for the bulk material itself (Lehnert and Kearfott, 2010a; Whetstone and Kearfott, 2014; Albright and Seviour, 2014). Many of these bulk detection methods are nuclear in nature and function through active interrogation with either photons or neutrons. While photon interrogation methods are relatively insensitive to explosive material due to similar electron densities with inert cargo, neutron interrogation has been widely studied due to high penetrating ability and direct interaction with target nuclei (Descalle et. al., 2006; Lehnert and Kearfott, 2010a; Gozani, 2011).

This paper presents a neutron interrogation-based algorithmic approach for screening for explosives inside standard $6.1 \mathrm{~m}$ long sea-land cargo containers. This method would most likely be used as a secondary screening strategy for suspicious containers, such as those whose contents deviate from the manifest or fail initial security screening and could be modified for use in other container sizes. The neutron interrogation entails irradiation with shielded monoenergetic 14.1 MeV neutrons. Neutron and photon measurements at different angles around the container are used to calculate flags, defined by specific mathematical manipulations of the neutron and photon spectra. A simple "yes/no" output is reached after combining specific flags in a series of steps that classifies the cargo material, identifies suspicious containers, and minimizes certain false positives. A major advantage of this approach is that combining neutron-based and photon-based detection strategies partially compensates for their respective shortcomings and furthermore maximizes signal carriers, reducing measurement time and personnel dose. 
Earlier papers on the algorithmic approach characterized the neutron scatter behavior of fast neutrons (Lehnert and Kearfott, 2010b) and compared simulations with measurements (Lehnert and Kearfott, 2012), laying the groundwork for further simulations. Later work identified promising flags in various conditions (Lehnert and Kearfott, 2011; Lehnert and Kearfott, 2014) and tested combinations of flags (Lehnert and Kearfott, 2014). This paper discusses combining these flags into a coherent explosives-detection algorithm and presents a screening system implementation.

\subsection{Equipment for explosives detection with neutron interrogation}

\subsubsection{Neutron sources}

Neutron sources for active neutron interrogation include isotropic sources, particle accelerators, and fusion-based neutron generators. A D-T neutron generator was chosen, as they are less expensive than most accelerator-based sources and provide the fast (14.1 MeV) monoenergetic neutrons required for the proposed method. Furthermore, a D-T neutron generator may be operated in pulse mode for time-of-flight (TOF) calculations and its compact geometry facilitates shielding and thus improves signal-to-noise (Whetstone and Kearfott, 2011). Another advantage is the availability of associated particle imaging (API) technology, which allows "tagging" incident neutrons of interest (Valkovic et. al., 2007; Valkovic et. al. 2009; Chichester et. al., 2005).

\subsubsection{Neutron detection}

Fast neutron detectors are based on neutron moderation, fast neutron interactions, or elastic recoil reactions (Lehnert and Kearfott, 2010a). The proposed method requires relatively high detection efficiency and at least crude neutron spectroscopy, which points to hydrogen-rich scintillators. Plastic and liquid scintillators are relatively inexpensive, easily formed into a wide variety of shapes and sizes, have fast response times, and can use pulse shape discrimination to differentiate between neutrons and photons (Dolan et. al., 2009; Knoll, 2010). 


\subsubsection{Photon detection}

Inorganic scintillators, such as thallium-doped sodium iodide $(\mathrm{NaI}(\mathrm{TI}))$ and bismuth germanate (BGO), are comparatively inexpensive modes of gamma spectroscopy and can have relatively high detection efficiencies, so were ideal for the proposed application. Other options, such as semiconductors and high-purity germanium detectors have superior energy resolution but are far more expensive and may have stringent cooling requirements (Knoll, 2010).

\subsection{Implementation of flag-based detection algorithm}

Previous simulations showed that flag values are strongly dependent on the identity of cargo material, which may furthermore differ from the manifest or be heterogeneous (Descalle et. al., 2006). One way to compensate for unknown or mistaken cargo is to use template-matching techniques to determine the material type. Alternatively, looking for changes in certain explosives-sensitive flags as a function of container position could indicate a hidden explosive, a strategy that is relatively independent of manifest accuracy or cargo type. Furthermore, multiple measurements are necessary for both strategies due to inadequate neutron penetration from a single irradiation.

In the proposed system the flag values at five irradiation points, as well as the average flag values for the entire container, are used in a decision tree-type algorithm to determine if explosives are present. In the first step, average values of material-sensitive flags determine the type of cargo present. Next, the presence of explosives is determined by searching for deviations in the value of explosives-sensitive flags as a function of position. An additional step would compare the average flag values with pure-explosives templates, in the event of a container filled with explosives. Finally, other steps would be included that minimize false positives, such as might result from heterogeneities in the cargo distribution.

\section{Materials and Methods}




\subsection{Monte Carlo simulations}

All simulations utilized either MCNP5 (Forster et. al., 2004) or MCNP-PoliMi (Pozzi et. al., 2003). The simulated neutron detector responses were calculated using PoliMi and a post-processor (Clarke et. al., 2012). All output text files were analyzed with a custom parser (MATLAB, 3 Apple Hill Drive, Natick, MA, USA 01760). MATLAB was also used to calculate the relevant flag values, flag strengths, and statistical uncertainty in flag calculations.

\subsubsection{Scanning geometry}

The simulations discussed here were based on the geometry shown in Fig. 1, with materials defined in Table 1. These simulations contained a sea-land cargo container with $2.4 \mathrm{~m}$ wide $\times 6.2 \mathrm{~m}$ long $\times 2.6 \mathrm{~m}$ high exterior dimensions and $0.346 \mathrm{~cm}$ thick steel walls. The container was surrounded by air and rested on a $25 \mathrm{~cm}$ concrete slab over soil. A rectangular hole $130 \mathrm{~cm}$ wide by $243 \mathrm{~cm}$ long by $210 \mathrm{~cm}$ deep in the slab and soil contained the shielded neutron source, with additional space provided for the $120^{\circ}$ and $150^{\circ}$ detectors. For the five irradiations, the container was shifted such that the source faced the container at locations of $62 \mathrm{~cm}, 186 \mathrm{~cm}, 310 \mathrm{~cm}, 434 \mathrm{~cm}$, and $558 \mathrm{~cm}$ from the container end.

\subsubsection{Neutron and photon detection}

Eleven cylindrical liquid scintillator detectors were distributed in $30^{\circ}$ intervals at a distance of $2.25 \mathrm{~m}$ from the center of the container. Each had a radius of $40 \mathrm{~cm}$ and a thickness of $20 \mathrm{~cm}$. EJ-309, as detailed in Table 1, was chosen for neutron detection and spectroscopy, due to its demonstrated pulse discrimination capabilities (Dolan et. al., 2009; Enqvist, 2013). Current, or MCNP5 F1, tallies sorted photons and neutrons into $0.2 \mathrm{MeV}$ energy bins and symmetrical, i.e. same scatter angle, detectors were combined into the same tally. Due to isotropic emission, all photon tallies were combined into one tally. Neutron detector response functions were calculated in each detector using MCNP-PoliMi and a postprocessor. 


\subsubsection{Neutron source}

Simulations of the five-scan screening technique required a fan-shaped beam with some overlap in irradiated volume. This beam came from an isotropic D-T neutron source placed at the bottom of the rectangular well behind at least $50 \mathrm{~cm}$ of shielding, as illustrated in Figs. 1 and 2. The shield's composition was equivalent to an equal volume mixture of polyethylene and steel. The opening of the shield projected a $70 \mathrm{~cm} \times 244 \mathrm{~cm}$ area on the facing container surface, which permitted full container width irradiation and 10\% length-wise overlap between the five measurements.

\subsubsection{Container cargo}

Several types and distributions of cargo inside the cargo container were used in the simulations. For the single-irradiation simulations that identified the material-sensitive flags, the inert materials were distributed evenly throughout the container volume with a density of $0.2-0.6 \mathrm{~g} \mathrm{~cm}^{-3}$ (Descalle et. al., 2006). Cargo was also homogeneously distributed in the five-scan simulations that found appropriate triggering thresholds in the detection algorithm. Inert cargos included cloth, electronics, furniture, paper, steel, vegetables, and wheat, as defined in Table 1. Other simulations used for the final step in the algorithm included $500 \mathrm{~kg}$ spheres of artificially-dense inert material inside homogenously distributed cargos of the same material.

\subsubsection{Cargo container on a trailer bed}

One potential difficulty in implementation of the algorithm is that the simulated conveyance of a moving surface or rail system would be impractical in a seaport environment. An alternative geometry was simulated in which the container was carried on a flatbed trailer with a $10 \mathrm{~cm}$ thick aluminum deck, six sets of two vulcanized rubber tires, and three steel axles, as shown in Fig. 3. 


\subsection{Determination of the explosives-detection algorithm}

The proposed algorithm involves the four steps detailed below. These steps require the calculation of three different types of flags: material-sensitive, explosives-detection, and density-discriminatory flags.

\subsubsection{Specification of cargo material}

The identification of the material-sensitive flags utilized simulations of homogenous cargo listed in Table 1. The chosen flags displayed the most consistent values within a cargo type (organic/hydrogenous or inorganic/metallic) and the largest difference in average flag value compared to the other cargo type. The material-sensitive flags were then organized into a sub-algorithm by finding threshold flag values that successfully categorized cargo materials. This was accomplished through an iterative process of trial and error.

\subsubsection{Identification of explosives-filled containers}

It is also possible that the entire container could be filled with explosives. Therefore a step was included that identifies this type of threat through comparison with templates of certain flag values or flag ratios. A preliminary database of these templates was created using simulations of containers homogeneously filled with the eleven explosive materials listed in Table 2.

\subsubsection{Triggering in the presence of hidden explosives}

The next step in the algorithm involved the actual triggering in the presence of hidden explosives using the previously identified explosives-detection flags (Lehnert and Kearfott, 2014) as a function of position. Cases without explosives were also examined to determine appropriate triggering thresholds based on the highest flag values in inert cargo.

\subsubsection{Minimization of false positives due to cargo heterogeneity}

The final step of the explosives-detection algorithm involved minimizing false positives due to heterogeneities in inert cargo distribution. To identify the 
density-discriminatory flags for this step, flag values for cases with artificially dense inert cargo heterogeneities were compared with those for cases with RDX. Flags were identified that triggered only in the presence of explosives as well as those that triggered only in the presence of inert, dense objects.

\subsection{Estimates of dose to personnel and cargo activation}

An important concern is the expected radiation dose to both operators and people hidden inside a container during screening (Hupe and Ankerhold, 2006). Dose was calculated using MCNP-PoliMi for the worst-case scenario in which an empty container went through all five scans of the explosives-detection system. Dose was estimated by multiplying the tallied neutron and photon fluence (MCNP F5) at a point by dose conversion factors found in ICRP Publication 74 (ICRP, 1997) and ICRU Report 47 (ICRU, 1992). A sufficient number of histories were simulated to keep statistical uncertainty below $2 \%$.

Dose was calculated at seventeen separate points in and around the container. Outside the container, six calculations were made in one-meter increments from $2 \mathrm{~m}$ to $7 \mathrm{~m}$ from the container center normal to the long side. Dose calculations inside the container were made centered above the scan 1, scan 2, and scan 3 positions at a height of $9 \mathrm{~cm}, 62 \mathrm{~cm}$, and $128 \mathrm{~cm}$ from the container floor. Finally, two additional calculations were performed $128 \mathrm{~cm}$ from the floor above the scan 3 position, but displaced laterally $60 \mathrm{~cm}$ and $120 \mathrm{~cm}$ from the center of the container.

Also considered was the residual activity when neutrons activate cargo materials. The interactions with the highest potential of significantly activating cargo appear in Table 3 (Erdtmann, 1976; Smith and Micklich, 2005). Two worst-case scenarios were considered, one in which the entire cargo was aluminum, and another with a cargo of rock salt $(\mathrm{NaCl})$. Another calculation utilized a cargo of potatoes, with the thought that any activation is more of a concern if the cargo is meant for human consumption. Calculations were carried out using activation software based on standard decay and cross section data (Mughabghab, 2003; NNDC, 2012). 


\section{Results and Discussion}

\subsection{Detection algorithm}

A diagram of the algorithm structure is shown in Fig. 4. Due to time and financial constraints discussed later, the proposed method would most likely be used as a secondary screening for suspicious containers, such as those whose contents differ from the manifest or fail earlier security screening. Because many of the best flags required stringent neutron spectroscopy (Lehnert and Kearfott, 2011; Lehnert and Kearfott, 2014), two variations in the algorithm are presented. Although very similar in structure, the spectroscopic variation uses all of the best-performing flags (Lehnert and Kearfott, 2011; Lehnert and Kearfott, 2014), while the Pulse Height Distribution (PHD) algorithm is limited to the best-performing flags that do not require unfolding of the neutron pulse height distribution (Lehnert and Kearfott, 2014).

\subsubsection{Identification of explosives-filled containers}

The first step in the algorithm was the identification of any cargo containers that is filled entirely with explosive by comparing with a stored template. Relative flag values, normalized to a single flag, were used instead of absolute flag values. A set of preliminary templates for several explosives: cyclotrimethylenetrinitramine (RDX), trinitrotoluene (TNT), fertilizer, and ethylene glycol dinitrate (EGDN), are shown in Table 4.

\subsubsection{Materials determination}

Five flags were identified for both algorithm variations that best classified cargo as organic/hydrogenous or metallic/inorganic. These are shown in the first two columns of Table 5, with threshold values listed in column three. Step four of the material sub-algorithm, shown in Fig. 4, was not needed in the PHD algorithm. Testing of the materials algorithm showed correct sorting into the two categories for all of the homogenously cargos studied here. As expected, performance in the case of heterogeneously distributed or mixed cargo, such as furniture, was more variable. 


\subsubsection{Triggering in the presence of hidden explosives}

The explosives-detection flags, changes in which signal possible explosives, are listed in Tables 6a and 6b (Lehnert and Kearfott, 2011; Lehnert and Kearfott, 2014). The triggering technique identified here first requires calculation of the height $(h)$ of each flag at all positions $(p)$. Height is defined as:

$$
h_{p=i}=\frac{f_{p=i}-\frac{\sum_{p \neq i} f_{p}}{4}}{\frac{\sum_{p \neq i} f_{p}}{4}}
$$

in which $f_{p=i}$ is the flag value at position $i$. The peak height for the flag $\left(h_{f}\right)$ is defined as the maximum $h_{p}$ value for that particular flag. Peak height is the maximum percent difference between a flag value at one position and the average value for the other four positions. To compare the peak heights of different flags, the $h_{p}$ values are shifted such that the minimum value is at zero. This is illustrated in Fig. 5 for the case of a large explosive hidden at position four that creates a systematic increase in flag height of several flags at that position. Finally, the trigger value $\left(h_{t}\right)$, defined as the maximum peak height over all relevant flags, is compared with a threshold value to determine if explosives are present. Trigger values in cases without explosive exceeded 0.1 in only one case, so a trigger value of 0.1 was chosen as the threshold value. However, as illustrated in Fig. 6 , about $40 \%$ of inert materials exhibited higher trigger values at an edge position, which required a higher threshold of 0.2 at these positions.

\subsubsection{Minimization of false positives due to cargo heterogeneity}

The flags used in minimizing false positives due to cargo heterogeneity are listed in Table 7. Trigger values for these flags were calculated in the same manner as discussed above. If the trigger value of the density-only flags was greater than those for the explosives-only flags, the possible explosive was dismissed as an inert object. 


\subsection{Implementation of the explosives-detection algorithm}

\subsubsection{Neutron source}

Implementation of the explosives-detection algorithm requires a fan-shaped beam of mostly monoenergetic neutrons, such as that produced by a commercially-available D-T neutron generator. D-T generators have typical production rates of $5 \times 10^{8}$ to $2 \times 10^{10} \mathrm{n} \mathrm{s}^{-1}$. The generator shield has $50 \mathrm{~cm}$ thick walls of polyethylene and steel that produces a beam $2.6 \mathrm{~m}$ by $0.62 \mathrm{~m}$ at the surface of the container closest to the source, as shown in Figs. 1 and 2. Calculations based on statistical uncertainty in the simulation (Lehnert and Kearfott, 2010b) and detection efficiency showed that $9 \times 10^{10}$ incident neutrons per scan are sufficient to produce statistical uncertainties of less than $2 \%$ in all flag calculations.

\subsubsection{Supporting infrastructure}

Transport through the scanning apparatus utilizes a conveyor that carries the container over the neutron source under a roughly circular scaffold holding the detectors equidistant from the container center. In order to maximize detection efficiency the scaffold radius should be as small as possible, so a distance of $2.5 \mathrm{~m}$ from container center, or at least $0.58 \mathrm{~m}$ from container edge, was chosen. The conveyor system may be either ground-based, i.e. rollers, or crane-based, suspending the containers from above.

One alternative to a conveyor-based system would be a flatbed truck. Simulations of the truck-based conveyance shown in Fig. 3 found that the wheels and axles significantly raised trigger values in the first scanning position, as illustrated in Fig. 7. Therefore, future versions of the system could only use a wheeled conveyance if the wheels are evenly distributed or correction factors are included.

\subsubsection{Photon detection}

To maximize detection efficiency, several large photon detectors should be placed on the scaffold such that interference from the source is minimized 
through either shielding or distance. As the algorithm only requires $0.2 \mathrm{MeV}$ energy resolution, an inorganic scintillator, such as $\mathrm{NaI}(\mathrm{TI})$ or BGO is sufficient. $\mathrm{Nal}(\mathrm{Tl})$ crystals have good light output, sufficient energy resolution, and over $75 \%$ intrinsic efficiency when $10 \mathrm{~cm}$ thick (Knoll, 2010). Large $(10 \mathrm{~cm} \times 41 \mathrm{~cm}$ ) detectors of this thickness have been tested for use in portal monitors (Reeder and Stromswold, 2004). An array of 12 of these detectors would count approximately $8 \times 10^{8}$ photons in the two minute period, which would yield statistical uncertainties of $\sim 3 \%$.

\subsubsection{Neutron detection}

Currently available neutron spectroscopy technology makes implementation of the spectroscopic difficult. However, the PHD algorithm was designed such that all neutron-based flags could be calculated using the response functions of EJ-309 liquid scintillators. The presented system includes eleven large EJ-309 neutron detectors distributed along the scaffold in $30^{\circ}$ increments. These large neutron detectors have a $40 \mathrm{~cm}$ diameter and are $20 \mathrm{~cm}$ thick.

\subsection{Measurement time, throughput and the total number of neutrons}

Simulations of the presented system utilized $5 \times 10^{9}$ particle histories and yielded flag value statistical uncertainties of $<3 \%$ for all but a few of the neutron flags in the spectroscopic algorithm, which were $5-8 \%$. When the $-20 \%$ intrinsic efficiency of the neutron detectors, $\sim 40 \%$ intrinsic efficiency (Reeder and Stromswold, 2004) and cross-sectional area of the photon detectors are considered, a total of $9 \times 10^{10}$ incident neutrons are needed per scan to maintain the statistical uncertainty levels. This leads to a measurement time approximately 1 min per scan, depending on the operating intensity of the neutron source. When the five irradiations, as well as physical positioning and transit are considered, total scanning time is approximately 10 minutes per container. This rate means that the system should either function as a secondary screening 
system, or several systems will be required at a given seaport. Measurement time could decrease to 5-6 minutes given the most powerful neutron generator.

\subsection{Estimated cost}

The production costs of the proposed system are reasonable, with the largest single expense the D-T neutron generator at around $\$ 300,000$. The eleven neutron detectors, associated digitization, power hardware and computer should cost between $\$ 190,000$ and $\$ 200,000$. The $\mathrm{Nal}(\mathrm{TI})$ photon detection system will cost another $\$ 70,000-\$ 100,000$ (Stromswold et. al., 2005). Other costs will include shielding materials and the physical infrastructure of the detector structure and conveyance system for the containers. In all, the equipment needed for the system will be approximately $\$ 1 \mathrm{M}$. Once the system is operational costs should be minimal, as the algorithm will be automated and operators will need little training.

\subsection{Estimated dose}

The estimated doses for ten locations in and around the container during a single five-scan application with $9 \times 10^{10}$ neutrons per scan are shown in Table 8 . As expected, the highest dose rates were near the container floor. However, the calculations show that a concealed individual would receive between $0.150 \mathrm{mSv}$ and $0.405 \mathrm{mSv}$; less than the $6.2 \mathrm{mSv}$ average annual dose and similar to that in a chest x-ray (NCRP, 2009). An operator, assuming six scans per hour and 2,000 hours worked per year, would be exposed to the radiation of approximately 12,000 scans. Without any added shielding an operator standing $5 \mathrm{~m}$ from the center of the container would receive a dose of approximately $39 \mathrm{mSv}$ per year. While this does not exceed the $50 \mathrm{mSv}$ U.S. occupational dose limit, adding $1 \mathrm{~m}$ of concrete shielding decreases operator dose to $0.86 \mathrm{mSv}$.

It was calculated that the total activity in $21,600 \mathrm{~kg}$ cargo was $2.4 \mathrm{MBq}$ for the rock salt and $160 \mathrm{MBq}$ in the aluminum. This level of radioactivity is insufficient to cause significant dose in personnel. Furthermore, most activity is due to nuclides $\left({ }^{38} \mathrm{Cl},{ }^{28} \mathrm{Al}\right)$ with half-lives on the order of minutes. A calculation for $21,600 \mathrm{~kg}$ of potatoes yielded a total induced activity of approximately 2.1 
$\mathrm{kBq}$, mostly from radionuclides such as ${ }^{19} \mathrm{O},{ }^{49} \mathrm{Ca}$, and ${ }^{42} \mathrm{~K}$, with half-lives of $27 \mathrm{~s}$, $8.7 \mathrm{~min}$, and $12 \mathrm{~h}$, respectively. Therefore, neutron activation of cargo in the proposed system is of trivial concern.

\section{Conclusions}

An active neutron interrogation-based explosives-detection system has been presented that uses measurements at five different locations to determine the presence and approximate location of explosives hidden in cargo containers. The detection algorithm relies on both neutron and photon emissions from neutron interactions in cargo by calculating flags formed from specific ratios of these measurements. These flags are used in an algorithm that includes steps for cargo identification, identification of concealed explosives, and the minimization of false positives due to cargo heterogeneity. An additional step identifies containers filled with explosives based on template matching. Implementation of the detection algorithm requires eleven liquid scintillator neutron detectors with pulse shape discrimination capabilities as well as several inorganic scintillators for photon spectroscopy. Dose estimates are well within acceptable levels for both system operators and concealed persons. Materials for the proposed system should cost approximately $\$ 1 \mathrm{M}$, and will be able to screen containers at a rate of at least six per hour.

\section{Acknowledgements}

The authors would like to thank Dr. Sara Pozzi, Eric Miller and Jennifer Dolan for their expertise and assistance in the use of the Monte Carlo postprocessor. This research was performed under appointment to the Department of Homeland Security (DHS) Scholarship and Fellowship Program, administered by the Oak Ridge Institute for Science and Education (ORISE) through an interagency agreement between the US Department of Energy (DOE) and DHS. ORISE is managed by Oak Ridge Associated Universities (ORAU) under DOE contract number DE-AC05-06OR23100. All opinions expressed in 
this paper are the authors' and do not necessarily reflect the policies and views of DHS, DOE, or ORAU/ORISE.

\section{References}

Albright, S., Seviour, R., 2014. Fusion Based Neutron Sources for Security Applications: Neutron Techniques. Proceedings of the 5th JACoW.

Chichester, D.L., Lemchak, M. Simpson, J.D., 2005. The API 120: A portable neutron generator for the associated particle technique. Nucl. Instrum. Methods Phys. Res. B. 241, 753-758.

Clarke, S.D., Flaska, M., Miller, E. C., Padocani, E., Pozzi, S., Prasad, S., 2012. MCNPX-PoliMi post-processing algorithm for detector response simulations. J. Nucl. Mater. Manag. 40, 34

Descalle, M.-A., Manatt, D., Slaughter, D., 2006. Analysis of recent manifests for goods imported through US ports. Report UCRL-TR-225708, Lawrence Livermore National Laboratory.

Dolan, J.L., Flaska, M., Pozzi, S., Chichester, D.L., 2009. Measurement and characterization of nuclear material at Idaho National Laboratory. Report INL/CON-09-16103, Idaho National Laboratory.

Enqvist, A., Lawrence, C. C., Wieger, B. M., Pozzi, S. A., Massey, T. N., 2013. Neutron light output response and resolution functions in EJ-309 liquid scintillation detectors. Nucl. Instrum. Methods Phys. Res. A. 715, 79-86.

Erdtmann, G., 1976. Neutron activation tables, Verlag Chemie, New York.

Forster, R.A., Cox, L.J., Barrett, R.F., Booth, T.E., Briesmeister, J.F., Brown, F.B., Bull, J.S., Geisler, G.C., Goorley, J.T., Mosteller, R.D., Post, S.E., Prael, R.E., Selcow, E.C., Sood, A., 2004. MCNP Version 5. Nucl. Instrum. Methods Phys. Res. B 213 82-86.

Gozani, T., 2011. Principles and status of neutron-based inspection technologies. SPIE Defense, Security, and Sensing. 8017. 
Hupe, O., Ankerhold, U., 2006. Determination of ambient and personal dose equivalent for personnel and cargo security screening. Radiat. Prot. Dosim. 121, 429-437.

International Commission on Radiation Protection (ICRP), 1997. Conversion coefficients for use in radiological protection against external radiation. Oxford: ICRP Publication 74.

International Commission on Radiation Units and Measurements (ICRU), 1992. Measurement of Dose Equivalents from External Photon and Electron Radiations. Report 47, Bethesda, MD.

Knoll, G.F., 2010. Radiation detection and measurements, third ed., John Wiley and Sons, Inc., Ann Arbor, Michigan, 2010.

Lehnert, A.L., Kearfott, K.J., 2010a. The detection of explosive materials: review of considerations and methods. Nucl. Technol. 172, 325-334.

Lehnert, A.L., Kearfott, K.J., 2010b. Simplified simulation of fast neutron scattering for an explosives detection application. Nucl. Sci. Eng. 168, 278-286.

Lehnert, A.L., Kearfott, K.J., 2011. Preliminary identification of flags for a novel algorithm-based approach for explosives detection using neutron interrogation for a simulated idealized cargo container scenario. Nucl. Instrum. Methods Phys. Res. A. 638, 201-205.

Lehnert, A.L., Kearfott, K.J., 2012. D-D neutron scatter measurements for a novel explosives detection technique. Nucl. Instrum. Methods. Phys. Res. A. 693, 195-202.

Lehnert, A.L., Kearfott, K.J., 2014. Simulations for Developing a Flag-Based Active Neutron Interrogation Method For Explosives Detection in SeaLand Cargo Containers, Nucl. Technol. 188, 97-111.

Mughabghab, S.F., 2003. Thermal neutron capture cross sections resonance integrals and G-factors. International Nuclear Data Committee, Report INDC(NDS)-440.

National Council on Radiation Protection and Measurements, 2009. lonizing radiation exposure of the population of the United States. Report 160. 
National Nuclear Data Center, "NuDat", Brookhaven National Laboratory, available at: http://www.nndc.bnl.gov/nudat2/

Pozzi, S., Padovani, E., Marseguerra, M., 2003. MCNP-PoliMi: a Monte-Carlo code for correlation measurements. Nucl. Instrum. Methods Phys. Res. A. $513,550-558$.

Reeder, P.L., Stromswold, D.C., 2004. Performance of large Nal(TI) gamma-ray detectors over temperature $-50^{\circ} \mathrm{C}$ to $+60^{\circ} \mathrm{C}$. Report PNNL-14735, Pacific Northwest National Laboratory, Richland, WA.

Safe Port Act, 2006. H.R. 4954 became Public Law No. 109-347

Smith, D.L., Micklich, B.J., 2005. Neutron activation data for neutron interrogation. AIP Conf. Proc. 769, 1698-1701.

Stromswold, D.C., Siciliano, E.R., Schweppe, J.E., Ely, J.H., Milbrath, B.D., Kouzes, R.T., Geelhood, B.D., 2005. Comparison of plastic and Nal(TI) scintillators for vehicle portal monitor applications. Nucl. Instrum. Methods Phys. Res. A, 550, 647-674.

Valkovic, V., Sudac, D., Blagus, S., Nad, K., Obhodas, J., Vekic, B., Nebbia, G., Pesente, S., 2007. Fast neutron inspection of sea containers for the presence of 'dirty bomb'. Nucl. Instrum. Methods Phys. Res. B. 263, 119-122.

Valkovic, V., Sudac, D., Matika, D., 2009. Fast neutron sensor for detection of explosives and chemical warfare agents. Appl. Radiat. Isot. 68, 888-892.

Whetstone, Z., Kearfott, K., 2011. Use of multiple layers of repeating material to effectively collimate an isotropic neutron source. Nucl. Technol. 176(3), 395-413.

Whetstone, Z., Kearfott, K., 2014. A review of conventional explosives detection using active neutron interrogation. J. Radioanal. Nucl. Chem. 301(3), 629639. 


\section{Figures}

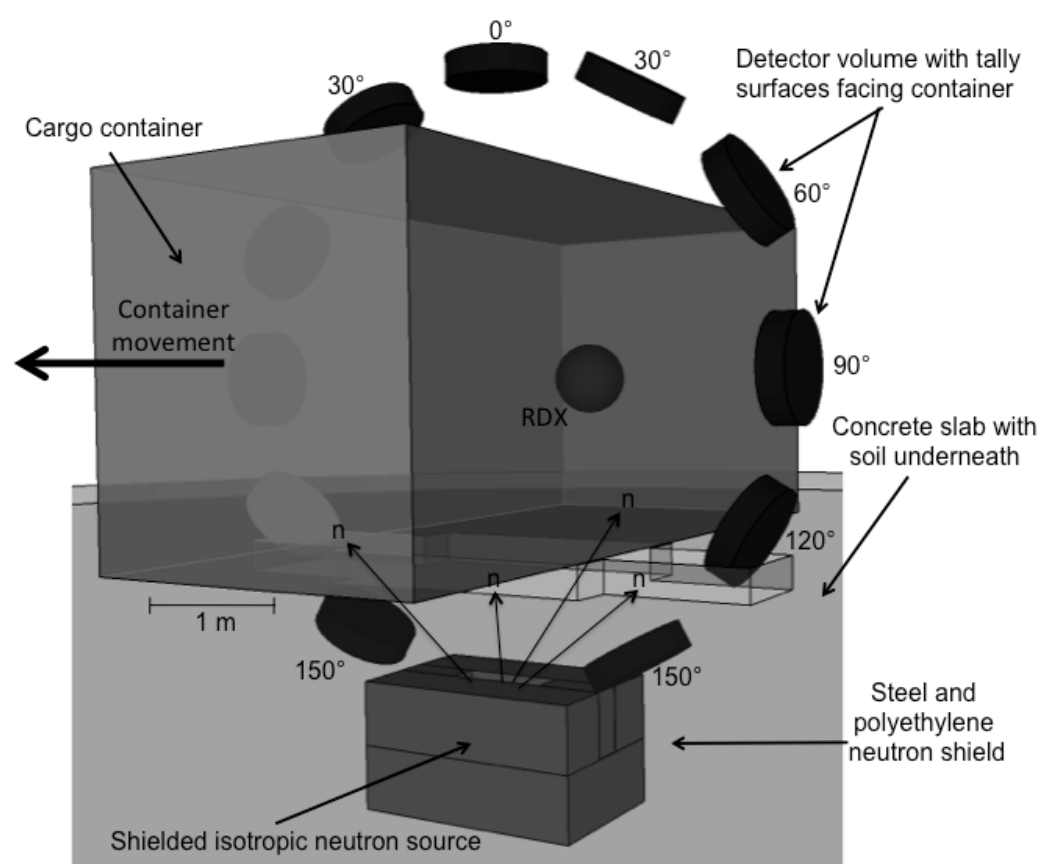

Figure 1. Illustration of container scanning geometry with empty container, except for explosive, located within ring of eleven detectors and over a shielded D-T neutron source. Irradiations take place at five locations along container as it moves through the detector array. 


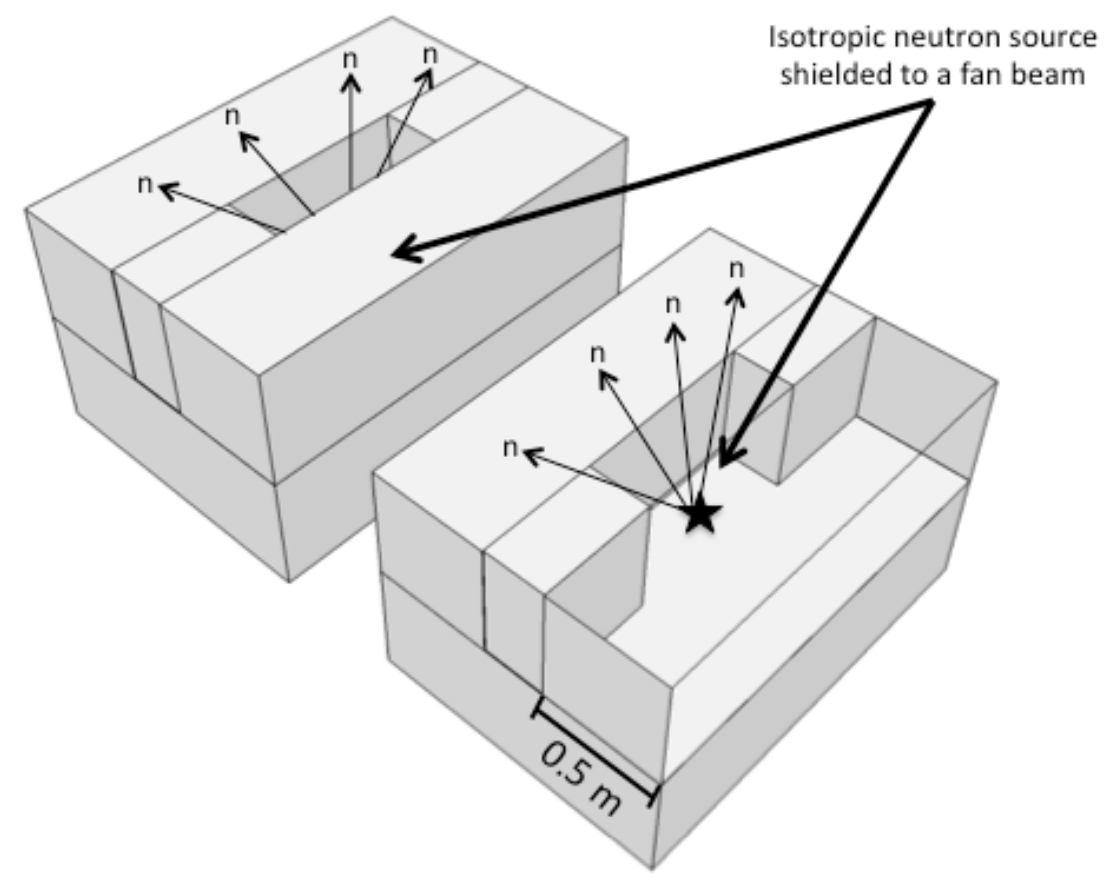

Figure 2. Detail of source shield of isotropic neutron source, producing a fan beam. 


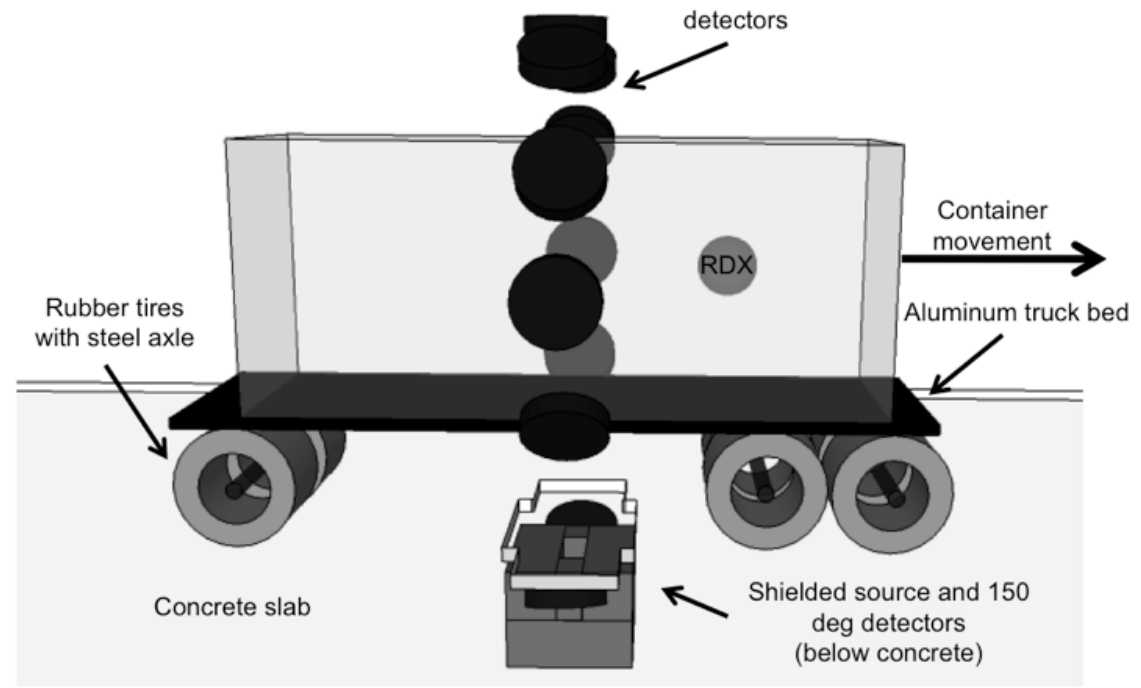

Figure 3. Alternative geometry with vehicular transport of container through the scanning apparatus 


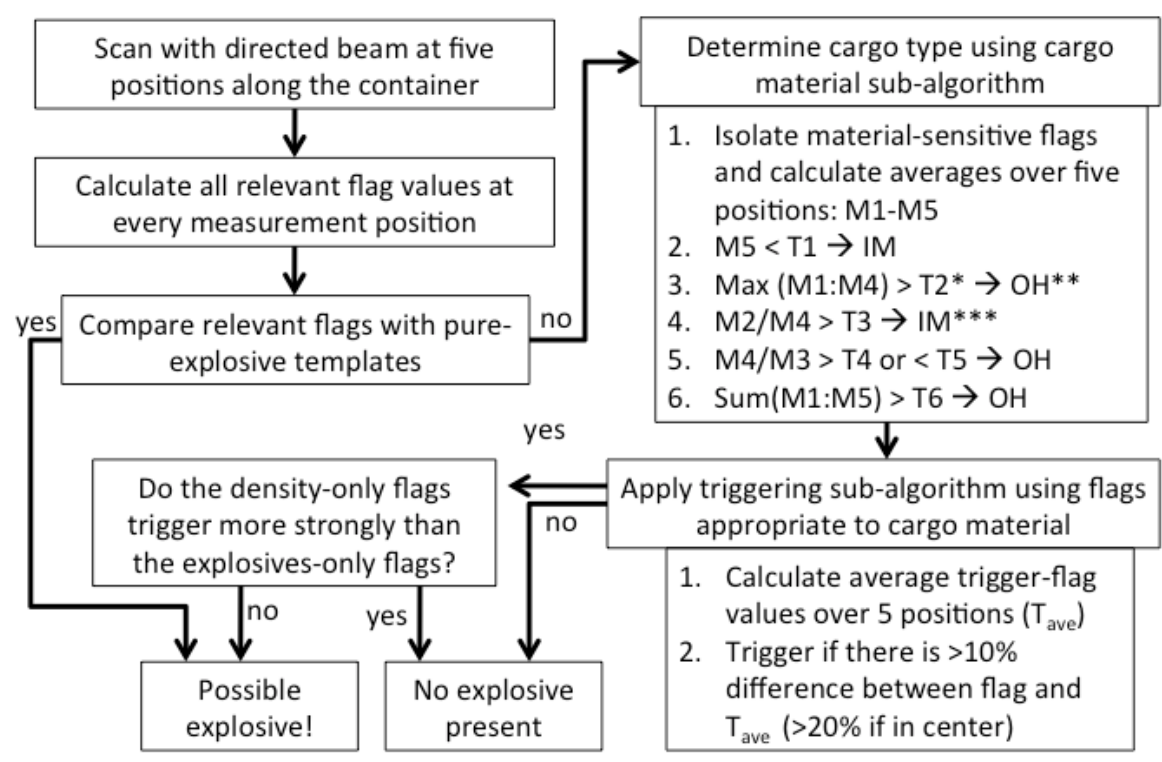

*T1-T5 thresholds: differ for spectroscopic/PHD

** Organic/Hydrogenous

***Inorganic/Metallic

Figure 4. Flow chart of explosives-detection algorithm 


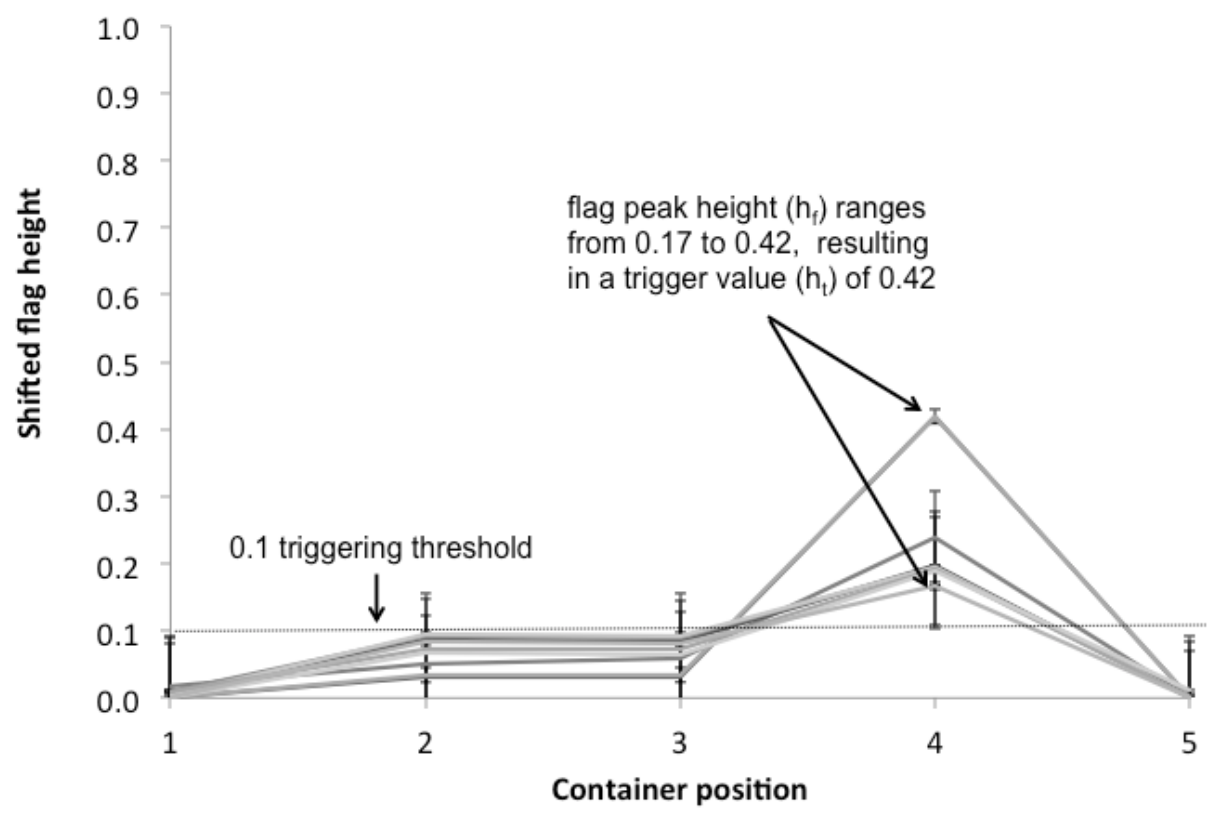

Figure 5. Example of change in explosives trigger flags as a function of container position for $300 \mathrm{~kg}$ of RDX at position 4 in a furniture-filled cargo container. Each line shows the response of one of the ten PHD explosives-detection flags in Table 6b. 


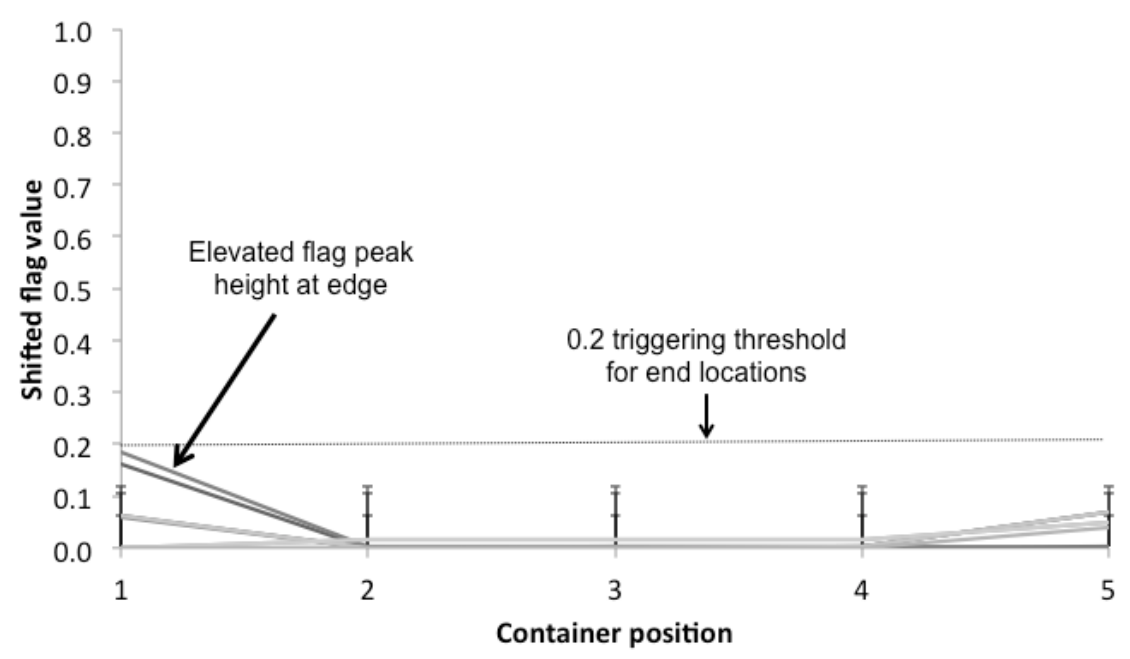

Figure 6. Example of the systematic bias in many cargo materials at the edge positions that mandates a 0.2 trigger threshold for these positions. In this example the container is homogenously filled with vegetable oil. 


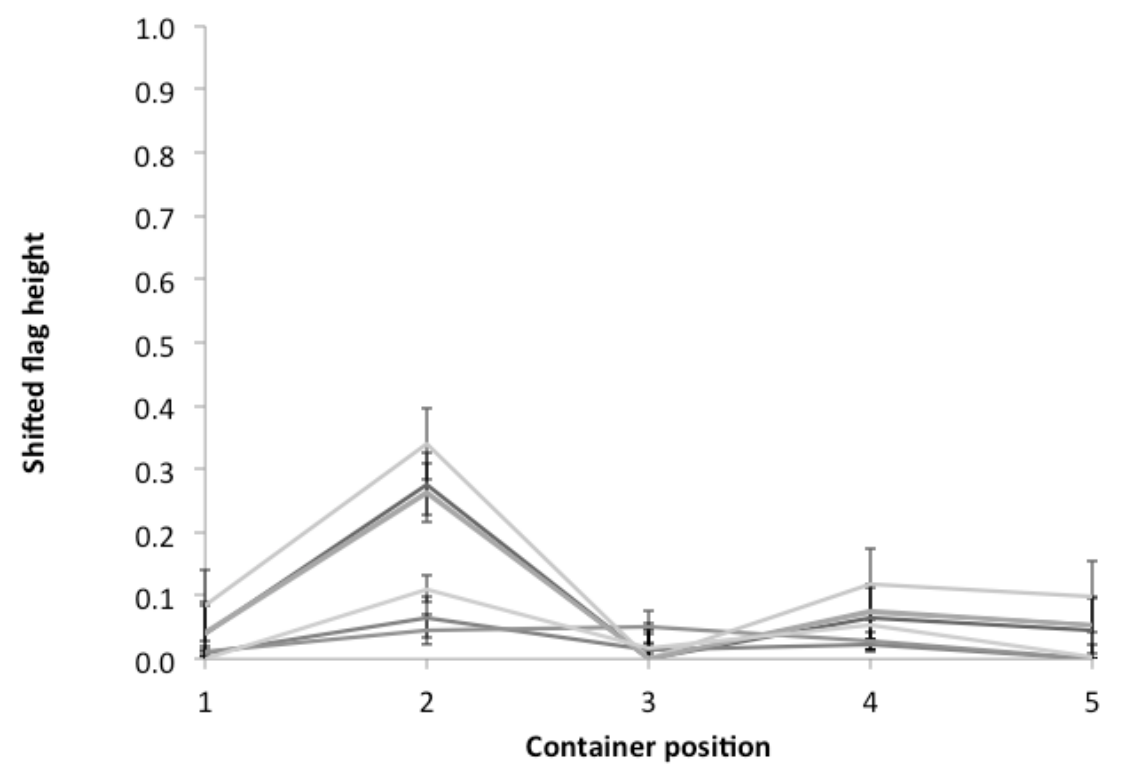

a.

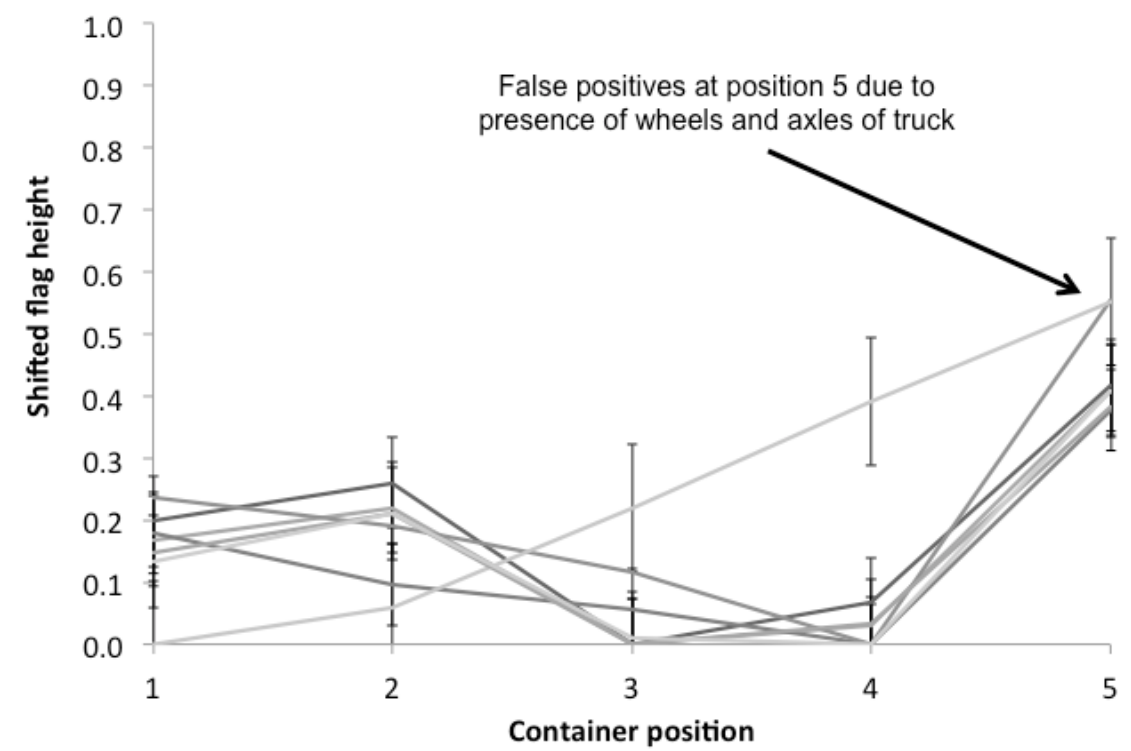

b.

Figure 7. Comparison of flag heights for a) conveyor based and b) truck based transport through scanning apparatus 


\section{Tables}

\section{Table 1}

Densities and compositions, expressed as atom percents, of inert materials used in MCNP simulation geometry, as adapted from (Lehnert and Kearfott, 2010b; Lehnert and Kearfott, 2011; Lehnert and Kearfott, 2012b).

\begin{tabular}{|c|c|c|c|c|c|c|}
\hline Material & Density & $\mathrm{H}$ & $\mathrm{C}$ & $\mathrm{N}$ & $\mathrm{O}$ & Other \\
\hline Air & 0.0012 & & $0.01 \%$ & $75.5 \%$ & $23.2 \%$ & $1.3 \% \mathrm{Ar}$ \\
\hline Brick & & & & & $66 \%$ & $0.4 . \% \mathrm{Al}, 32 \% \mathrm{Si}, 1 \% \mathrm{Ca}$ \\
\hline EJ-309 & 0.916 & $55 \%$ & $45 \%$ & & & \\
\hline Concrete & 2.3 & $30.4 \%$ & $0.29 \%$ & & $49.9 \%$ & $\begin{array}{l}0.92 \% \mathrm{Na}, 1.03 \% \mathrm{Al}, 15.1 \% \mathrm{Si} \text {, } \\
0.71 \% \mathrm{~K}, 1.49 \% \mathrm{Ca}, 0.16 \% \mathrm{Fe}\end{array}$ \\
\hline Cotton & 1.1 & $48 \%$ & $29 \%$ & & $24 \%$ & \multirow{3}{*}{$\begin{array}{l}0.5 \% \mathrm{~S} \\
2.6 \% \mathrm{Al}, 12 \% \mathrm{Si}, 10 \% \mathrm{Ni}, 0.3 \% \\
\text { Fe }\end{array}$} \\
\hline Crude Oil & 0.97 & $62 \%$ & $37 \%$ & & & \\
\hline Electronics & 0.329 & $26 \%$ & $2 \%$ & & $47 \%$ & \\
\hline Furniture & 0.8 & $41 \%$ & $32 \%$ & & $21 \%$ & \multirow{4}{*}{$\begin{array}{l}3 \% \mathrm{Fe}, 3 \% \mathrm{Al} \\
2.6 \% \mathrm{Na}, 1.9 \% \mathrm{Mg}, 6.5 \% \mathrm{AL} \text {, } \\
21 \% \mathrm{Si}, 1.4 \% \mathrm{~K}, 2 \% \mathrm{Ca}, 2 \% \mathrm{Fe} \\
\text { trace K, P } \\
40 \% \mathrm{Si}\end{array}$} \\
\hline Granite & 2.73 & $0 \%$ & $0 \%$ & & $62 \%$ & \\
\hline Meat & 1.1 & $60 \%$ & $15 \%$ & $1 \%$ & $24 \%$ & \\
\hline Melamine & 1.57 & $40 \%$ & $20 \%$ & & & \\
\hline Vegetable oil & 0.918 & $63 \%$ & $34 \%$ & & $4 \%$ & \multirow{7}{*}{$\begin{array}{l}15 \% \mathrm{Ca}, 15 \% \mathrm{~S} \\
8.8 \% \mathrm{Na}, 25 \% \mathrm{Si}, 5.6 \% \mathrm{Ca}\end{array}$} \\
\hline Paraffin & 0.93 & $68 \%$ & $32 \%$ & & & \\
\hline Plaster & 0.85 & $7 \%$ & & & $63 \%$ & \\
\hline Plate Glass & 2.4 & & & & $60 \%$ & \\
\hline Polyester & 1.4 & $36 \%$ & $45 \%$ & & $18 \%$ & \\
\hline Polyethylene & 0.93 & $67 \%$ & $33 \%$ & & & \\
\hline Polystyrene & 1.06 & $50 \%$ & $50 \%$ & & & \\
\hline $\begin{array}{r}\text { Polyvinyl } \\
\text { chloride }\end{array}$ & 1.406 & $50 \%$ & $33 \%$ & & & $17 \% \mathrm{Cl}$ \\
\hline Rock Salt & 2.18 & & & & & \multirow{6}{*}{$\begin{array}{l}50 \% \mathrm{Na}, 50 \% \mathrm{Cl} \\
19 \% \mathrm{~S} \\
29.3 \% \mathrm{Si}, 3.8 \% \mathrm{Al}, 1.21 \% \mathrm{Ca} \\
99.6 \% \mathrm{Fe}, 0.05 \% \mathrm{~S}, 0.04 \% \mathrm{P} \\
2.59 \% \mathrm{Al}, 13.54 \% \mathrm{Si}, 1.43 \% \mathrm{~K} \text {, } \\
0.27 \% \mathrm{Fe}\end{array}$} \\
\hline Rubber & 1.1 & $50 \%$ & $31 \%$ & & & \\
\hline Sand & 1.6 & & & trace & $65.5 \%$ & \\
\hline Steel & 7.87 & & $0.32 \%$ & & & \\
\hline Soil & 1.75 & $29.4 \%$ & $1.87 \%$ & & $50.5 \%$ & \\
\hline Water & 1 & $67 \%$ & & & $33 \%$ & \\
\hline Wheat & 0.79 & $7 \%$ & $37 \%$ & $2 \%$ & $53 \%$ & $\begin{array}{l}\text { trace: } \mathrm{S}, \mathrm{Na}, \mathrm{K}, \mathrm{Ca}, \mathrm{Mg}, \mathrm{Fe} \\
\mathrm{Cu}, \mathrm{Zn}, \mathrm{P}, \mathrm{Cl}\end{array}$ \\
\hline Wood/paper & $0.6 / 0.3$ & $48 \%$ & $29 \%$ & & $24 \%$ & \multirow[b]{2}{*}{$\begin{array}{l}\text { trace } \mathrm{Ca}, \mathrm{Fe}, \mathrm{Mg}, \mathrm{P}, \mathrm{K}, \mathrm{Na}, \mathrm{S} \text {, } \\
\mathrm{Cl}\end{array}$} \\
\hline $\begin{array}{r}\text { Vegetables } \\
\text { (potatoes) } \\
\end{array}$ & 1.6 & $63 \%$ & $6 \%$ & & $31 \%$ & \\
\hline
\end{tabular}




\section{Table 2}

Explosive materials used to create explosive cargo templates, as adapted from (Lehnert and Kearfott, 2012b).

\begin{tabular}{ccccccc}
\hline Material & Density & $\mathrm{H}$ & $\mathrm{C}$ & $\mathrm{N}$ & $\mathrm{O}$ & Other \\
\hline $\begin{array}{c}\text { Acetone } \\
\text { Peroxide }\end{array}$ & 1.22 & $55 \%$ & $27 \%$ & & $18 \%$ & \\
$\begin{array}{c}\text { Ammonium } \\
\text { Nitrate }\end{array}$ & 1.73 & $44 \%$ & & $22 \%$ & $33 \%$ & \\
$\quad$ Black & 1.04 & $51 \%$ & $7 \%$ & $7 \%$ & $23 \%$ & $7.6 \% \mathrm{~K}, 3 \% \mathrm{Si}$ \\
Powder & & & & & & \\
EGDN & 1.49 & $29 \%$ & $14 \%$ & $14 \%$ & $43 \%$ & \\
Fertilizer & 0.99 & $0 \%$ & & & $0 \%$ & $1 \% \mathrm{Na}, 50 \% \mathrm{Cl}, 48 \%$ \\
HMX & 1.9 & $29 \%$ & $14 \%$ & $29 \%$ & $29 \%$ & \\
Nitrocellulose & 1.66 & $29 \%$ & $25 \%$ & $13 \%$ & $33 \%$ & \\
Nitroglycerin & 1.13 & $25 \%$ & $15 \%$ & $15 \%$ & $45 \%$ & \\
PETN & 1.77 & $29 \%$ & $17 \%$ & $14 \%$ & $41 \%$ & \\
RDX & 1.82 & $29 \%$ & $14 \%$ & $29 \%$ & $29 \%$ & \\
TNT & 1.65 & $24 \%$ & $33 \%$ & $14 \%$ & $29 \%$ & \\
\hline
\end{tabular}




\section{Table 3}

Important reactions induced activity from neutron activation of cargo materials, as adapted from (ICRU, 1992). Activity based on incident thermal flux of $10^{13} \mathrm{n}$ $\mathrm{cm}^{-2} \mathrm{~s}^{-1}$ and epithermal flux of $10^{11} \mathrm{n} \mathrm{cm}^{-2} \mathrm{~s}^{-1}$ (ICRP, 1997).

\begin{tabular}{|c|c|c|c|c|c|}
\hline Isotope & Reaction & Product & Half life & $\begin{array}{c}\text { Photons } \\
{[\mathrm{MeV}]}\end{array}$ & $\begin{array}{c}\text { Activity after } 1 \\
\text { min irradiation } \\
{\left[\mathrm{Bq} \mu \mathrm{g}^{-1}\right]}\end{array}$ \\
\hline${ }^{23} \mathrm{Na}$ & $(\mathrm{n}, \gamma)$ & ${ }^{24} \mathrm{Na}$ & $15.0 \mathrm{~h}$ & $1.37,2.75$ & 108 \\
\hline${ }^{26} \mathrm{Mg}$ & $(\mathrm{n}, \gamma)$ & ${ }^{27} \mathrm{Mg}$ & $9.46 \mathrm{~m}$ & $0.84,1.01$ & 74.7 \\
\hline${ }^{27} \mathrm{Al}$ & $(n, \gamma)$ & ${ }^{28} \mathrm{Al}$ & $2.24 \mathrm{~m}$ & $1.78,336$ & 14,000 \\
\hline${ }^{37} \mathrm{Cl}$ & $(n, \gamma)$ & ${ }^{28} \mathrm{Cl}$ & $37.2 \mathrm{~m}$ & $2.17,1.64$ & 332 \\
\hline${ }^{59} \mathrm{Co}$ & $(n, \gamma)$ & ${ }^{60} \mathrm{Co}$ & $1930 \mathrm{~d}$ & $1.33,1.17$ & 0.472 \\
\hline${ }^{63} \mathrm{Cu}$ & $(n, \gamma)$ & ${ }^{64} \mathrm{Cu}$ & $12.7 \mathrm{~h}$ & $0.51,262$ & 274 \\
\hline${ }^{116} \mathrm{Sn}$ & $(\mathrm{n}, \gamma)$ & ${ }^{117 m} \mathrm{Sn}$ & $13.6 \mathrm{~d}$ & 0.16 & 0.0039 \\
\hline
\end{tabular}




\section{Table 4}

Example of preliminary templates for several explosive-only cargos. Templates are based on the PHD detection algorithm.

\begin{tabular}{|c|c|c|c|c|}
\hline Flag & RDX & TNT & Fertilizer & EGDN \\
\hline$\frac{\left(>4.9 \mathrm{MeVee}, 150^{\circ}\right)}{\left(<0.14 \mathrm{MeVee}, 0^{\circ}\right)}$ & 1.00 & 1.00 & 1.00 & 1.00 \\
\hline$\frac{\left(2.1-4.9 \mathrm{MeVee}, 150^{\circ}\right)}{\left(2.1-4.9 \mathrm{MeVee}, 0^{\circ}\right)}$ & 1.16 & 1.10 & 1.47 & 1.10 \\
\hline$\frac{\left(>4.9 \mathrm{MeVee}, 120^{\circ}\right)}{\left(>4.9 \mathrm{MeVee}, 0^{\circ}\right)}$ & 0.66 & 0.61 & 0.45 & 0.64 \\
\hline$\frac{\left(>4.9 \mathrm{MeVee}, 150^{\circ}\right)}{\left(>4.9 \mathrm{MeVee}, 0^{\circ}\right)}$ & 1.27 & 1.19 & 0.94 & 1.25 \\
\hline$\frac{\left(>5.8 \mathrm{MeVee}, 150^{\circ}\right)}{\left(>4.9 \mathrm{MeVee}, 0^{\circ}\right)}$ & 0.73 & 0.69 & 0.57 & 0.72 \\
\hline$\frac{\left(>5.8 \mathrm{MeVee}, 120^{\circ}\right)}{\left(>5.8 \mathrm{MeVee}, 0^{\circ}\right)}$ & 0.67 & 0.65 & 0.42 & 0.65 \\
\hline$\frac{\left(>5.8 \mathrm{MeVee}, 150^{\circ}\right)}{\left(>5.8 \mathrm{MeVee}, 0^{\circ}\right)}$ & 1.26 & 1.25 & 0.85 & 1.23 \\
\hline$\frac{\left[\frac{\left(\text { total neutron }, 90^{\circ}\right)}{\left(\text { total neutron, } 0^{\circ}\right)}\right]}{(\mathrm{C} \text { photon })}$ & $\begin{array}{c}3.39 \times \\
10^{3}\end{array}$ & $2.46 \times 10^{3}$ & $5.93 \times 10^{3}$ & $3.31 \times 10^{3}$ \\
\hline$\left.-\frac{\left[\text { total neutron, } 150^{\circ}\right)}{\left(\text { total neutron, } 0^{\circ}\right)}\right]$ & $\begin{array}{c}1.13 \times \\
10^{4}\end{array}$ & $8.36 \times 10^{3}$ & $1.09 \times 10^{4}$ & $1.10 \times 10^{4}$ \\
\hline$\frac{\left[\frac{\left(\text { total neutron, } 150^{\circ}\right)}{\left(\text { total neutron, } 0^{\circ}\right)}\right]}{(\mathrm{N} \text { photon })}$ & $\begin{array}{c}2.99 \times \\
10^{3}\end{array}$ & $2.89 \times 10^{3}$ & $2.51 \times 10^{3}$ & $2.91 \times 10^{3}$ \\
\hline$\frac{\left[\frac{\left(\text { total neutron, } 150^{\circ}\right)}{\left(\text { total neutron, } 0^{\circ}\right)}\right]}{(\mathrm{O} \text { photon })}$ & $\begin{array}{c}2.16 \times \\
10^{4}\end{array}$ & $2.70 \times 10^{4}$ & $6.05 \times 10^{4}$ & $2.12 \times 10^{4}$ \\
\hline
\end{tabular}




\section{Table 5}

Identities of the top flags used in determining the type of cargo in an unknown container. Also shown are the average flag values for organic/hydrogenous cargos and metallic/inorganic cargos. Large standard deviations due to highly varying flag values even within one category.

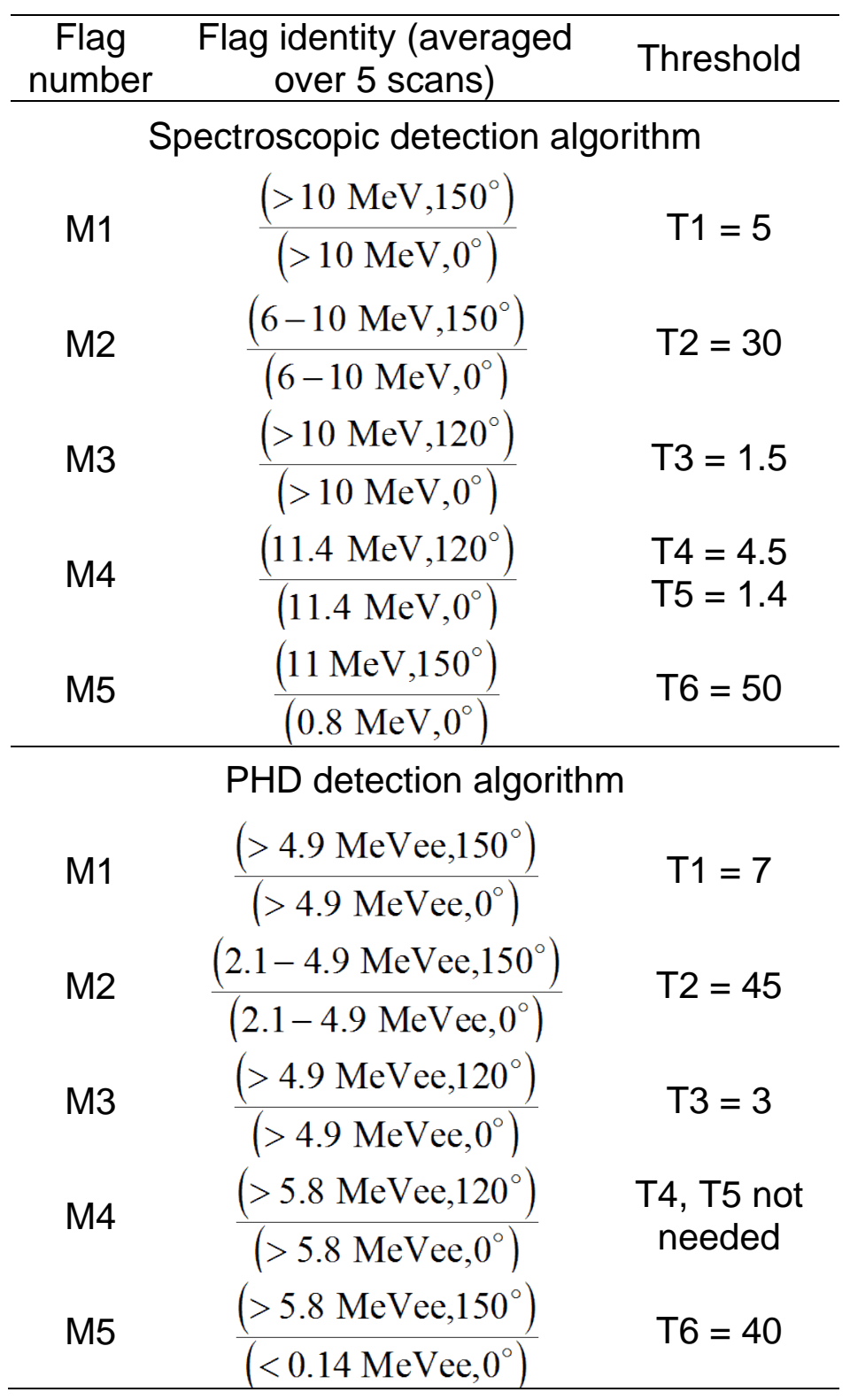




\section{Table 6a}

Identities of the top flags used in determining if explosives are present in an unknown container for a) Spectroscopic and b) PHD algorithm.

Spectroscopic algorithm

\begin{tabular}{|c|c|}
\hline \multicolumn{2}{|c|}{ Organic or hydrogenous cargo flags } \\
\hline \multirow{3}{*}{$\frac{\left(11 \mathrm{MeV}, 150^{\circ}\right)}{\left(11 \mathrm{MeV}, 0^{\circ}\right)}$} & (total neutron, $150^{\circ}$ ) \\
\hline & (total neutron, $\left.0^{\circ}\right)$ \\
\hline & C photon \\
\hline \multirow{2}{*}{$\left(11 \mathrm{MeV}, 150^{\circ}\right)$} & (total neutron, $90^{\circ}$ ) \\
\hline & (total neutron, $\left.0^{\circ}\right)$ \\
\hline$\overline{\left(10 \mathrm{MeV}, 0^{\circ}\right)}$ & C photon \\
\hline \multirow{2}{*}{$\left(11 \mathrm{MeV}, 150^{\circ}\right)$} & (total neutron, $150^{\circ}$ ) \\
\hline & (total neutron, $\left.0^{\circ}\right)$ \\
\hline$\overline{\left(9.6 \mathrm{MeV}, 0^{\circ}\right)}$ & O photon \\
\hline$\left(>10 \mathrm{MeV}, 120^{\circ}\right)$ & $\left(>10 \mathrm{MeV}, 180^{\circ}\right)$ \\
\hline$\overline{\left(>10 \mathrm{MeV}, 0^{\circ}\right)}$ & $\overline{\left(>10 \mathrm{MeV}, 0^{\circ}\right)}$ \\
\hline$\left(>10 \mathrm{MeV}, 150^{\circ}\right)$ & $\left(6-10 \mathrm{MeV}, 150^{\circ}\right)$ \\
\hline$\left(>10 \mathrm{MeV}, 0^{\circ}\right)$ & $\left(6-10 \mathrm{MeV}, 0^{\circ}\right)$ \\
\hline \multicolumn{2}{|c|}{ Metallic or inorganic cargo flags } \\
\hline \multirow{2}{*}{$\left(10.8 \mathrm{MeV}, 150^{\circ}\right)$} & (total neutron, $\left.150^{\circ}\right)$ \\
\hline & (total neutron, $0^{\circ}$ ) \\
\hline$\left(10.8 \mathrm{MeV}, 0^{\circ}\right)$ & C photon \\
\hline$\left(11.2 \mathrm{MeV}, 150^{\circ}\right)$ & (total neutron, $\left.150^{\circ}\right)$ \\
\hline \multirow{2}{*}{$\left(11.2 \mathrm{MeV}, 0^{\circ}\right)$} & (total neutron, $\left.0^{\circ}\right)$ \\
\hline & N photon \\
\hline \multirow{2}{*}{$\left(11.6 \mathrm{MeV}, 120^{\circ}\right)$} & (total neutron, $\left.150^{\circ}\right)$ \\
\hline & (total neutron, $0^{\circ}$ ) \\
\hline$\overline{\left(11.6 \mathrm{MeV}, 0^{\circ}\right)}$ & O photon \\
\hline$\left(>10 \mathrm{MeV}, 120^{\circ}\right)$ & $\left(11 \mathrm{MeV}, 150^{\circ}\right)$ \\
\hline$\left(>10 \mathrm{MeV}, 0^{\circ}\right)$ & $\left(10 \mathrm{MeV}, 0^{\circ}\right)$ \\
\hline$\left(>10 \mathrm{MeV}, 150^{\circ}\right)$ & $\left(>10 \mathrm{MeV}, 150^{\circ}\right)$ \\
\hline$\left(>10 \mathrm{MeV}, 0^{\circ}\right)$ & $\left(<1 \mathrm{MeV}, 0^{\circ}\right)$ \\
\hline
\end{tabular}




\section{Table 6b}

Identities of the top flags used in determining if explosives are present in an unknown container for a) Spectroscopic and b) PHD algorithm.

\begin{tabular}{|c|c|}
\hline \multicolumn{2}{|c|}{ PHD algorithm } \\
\hline \multicolumn{2}{|c|}{ Organic or hydrogenous cargo flags } \\
\hline$\left(>5.8 \mathrm{MeVee} 150^{\circ}\right)$ & {$\left[\right.$ (total neutron, $\left.150^{\circ}\right)$} \\
\hline$\left(>5.8 \mathrm{MeVee}, 0^{\circ}\right)$ & $\left(\right.$ total neutron, $\left.0^{\circ}\right)$ \\
\hline & C photon \\
\hline$\left(>58 \mathrm{MeVee} 150^{\circ}\right)$ & (total neutron, $\left.90^{\circ}\right)$ \\
\hline$\left(>4.9 \mathrm{MeVee}, 0^{\circ}\right)$ & $\left(\right.$ total neutron, $\left.0^{\circ}\right)$ \\
\hline & C photon \\
\hline$\left(>4.9 \mathrm{MeVee}, 120^{\circ}\right)$ & (total neutron, $\left.150^{\circ}\right)$ \\
\hline$\frac{\left(>49 \mathrm{MeVee} 0^{\circ}\right)}{(>4.9 \mathrm{n})}$ & $\left(\right.$ total neutron, $\left.0^{\circ}\right)$ \\
\hline 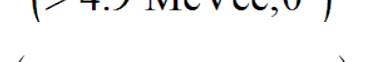 & O photon \\
\hline$\left(>4.9 \mathrm{MeVee}, 150^{\circ}\right)$ & $\left(2.1-4.9 \mathrm{MeVee}, 120^{\circ}\right)$ \\
\hline$\left(>4.9 \mathrm{MeVee}, 0^{\circ}\right)$ & $\left(2.1-4.9 \mathrm{MeVee}, 0^{\circ}\right)$ \\
\hline \multicolumn{2}{|c|}{ Metallic or inorganic cargo flags } \\
\hline$\left(>58 \mathrm{MeVee} 150^{\circ}\right)$ & (total neutron, $\left.150^{\circ}\right)$ \\
\hline$\frac{\left(>58 \mathrm{MeVee} 0^{\circ}\right)}{(-2.010100,100}$ & (total neutron, $0^{\circ}$ ) \\
\hline (> 5.8 Mevee, 0 ) & C photon \\
\hline$(>58)$ & (total neutron, $\left.150^{\circ}\right)$ \\
\hline$\left(>49 \mathrm{MeVee} 0^{\circ}\right)$ & (total neutron, $\left.0^{\circ}\right)$ \\
\hline$\left(>4.9\right.$ MeVee, $\left.0^{\circ}\right)$ & $\mathrm{N}$ photon \\
\hline$\left(>4.9 \mathrm{MeVee}, 120^{\circ}\right)$ & (total neutron, $\left.150^{\circ}\right)$ \\
\hline$\left(>49 \mathrm{MeVee} 0^{\circ}\right)$ & (total neutron, $0^{\circ}$ ) \\
\hline & O photon \\
\hline$\left(>4.9 \mathrm{MeVee}, 150^{\circ}\right)$ & $\left(>5.8 \mathrm{MeVee}, 120^{\circ}\right)$ \\
\hline$\left(>4.9 \mathrm{MeVee}, 0^{\circ}\right)$ & $\left(>5.8 \mathrm{MeVee}, 0^{\circ}\right)$ \\
\hline & $\left(>4.9 \mathrm{MeVee}, 150^{\circ}\right)$ \\
\hline & $\left(>0.14 \mathrm{MeVee}, 0^{\circ}\right)$ \\
\hline
\end{tabular}




\section{Table 7}

Identities of the best flags used in eliminating false positives due to the presence of inert objects of elevated density.

\begin{tabular}{|c|c|}
\hline $\begin{array}{l}\text { Organic or hydrogenous } \\
(\mathrm{OH}) \text { cargo flags }\end{array}$ & $\begin{array}{l}\text { Metallic or inorganic cargo } \\
\text { (IM) cargo flags }\end{array}$ \\
\hline \multicolumn{2}{|c|}{ Explosives only triggering flags } \\
\hline 6.2 MeV photon & 5.2 MeV photon \\
\hline$\overline{1.8 \mathrm{MeV} \text { photon }}$ & $\overline{3.8 \mathrm{MeV} \text { photon }}$ \\
\hline $6.2 \mathrm{MeV}$ photon & $\left[\right.$ (total neutron, $\left.\left.150^{\circ}\right)\right]$ \\
\hline $2.4 \mathrm{MeV}$ photon & $=\frac{\left(\text { total neutron, } 0^{\circ}\right)}{\mathrm{N} \text { photon }}$ \\
\hline $6.2 \mathrm{MeV}$ photon & (total neutron, $\left.90^{\circ}\right)$ \\
\hline$\overline{2.6 \mathrm{MeV} \text { photon }}$ & N photon \\
\hline $6.2 \mathrm{MeV}$ photon & $\frac{\left(\text { total neutron, } 90^{\circ}\right)}{\left(\text { total neutron, } 0^{\circ}\right)}$ \\
\hline $2.8 \mathrm{MeV}$ photon & O photon \\
\hline $6.2 \mathrm{MeV}$ photon & {$\left[\frac{\left(\text { total neutron }, 150^{\circ}\right)}{\left(\text { total neutron }, 0^{\circ}\right)}\right]$} \\
\hline 3.4 MeV photon & O photon \\
\hline \multicolumn{2}{|c|}{$\begin{array}{l}\text { Dense object only triggering flags } \\
\text { (same for } \mathrm{OH} \text { and IM cargos) }\end{array}$} \\
\hline $5.2 \mathrm{MeV}$ photon & $5.2 \mathrm{MeV}$ photon \\
\hline$\overline{1.0 \mathrm{MeV} \text { photon }}$ & $\overline{2.6 \mathrm{MeV} \text { photon }}$ \\
\hline 6.8 $\mathrm{MeV}$ photon & 4.6 $\mathrm{MeV}$ photon \\
\hline$\overline{1.0 \mathrm{MeV} \text { photon }}$ & $\overline{3.4 \mathrm{MeV} \text { photon }}$ \\
\hline 4. $6 \mathrm{MeV}$ photon & 5.2 $\mathrm{MeV}$ photon \\
\hline$\overline{2.6 \mathrm{MeV} \text { photon }}$ & $\overline{3.4 \mathrm{MeV} \text { photon }}$ \\
\hline
\end{tabular}




\section{Table 8}

Dose estimates at various locations for a single container scan consisting of one-minute irradiations with a $5 \times 10^{8} \mathrm{n} \mathrm{s}^{-1} \mathrm{D}-\mathrm{T}$ neutron generator.

\begin{tabular}{cc}
\hline Location & Dose $(\mathrm{mSv})$ \\
\hline 2 m outside container center & 0.378 \\
3 m outside container center & 0.00606 \\
4 m outside container center & 0.0321 \\
5 m outside container center & 0.00321 \\
5 m outside container center, shielded & 0.0000717 \\
6 m outside container center & 0.00200 \\
7 m outside container center & 0.00136 \\
Centered above scan 1 & 0.151 \\
Centered above scan 2 & 0.167 \\
Centered above scan 3 & 0.169 \\
$62 \mathrm{~cm}$ from floor above scan 1 & 0.224 \\
$62 \mathrm{~cm}$ from floor above scan 2 & 0.230 \\
$62 \mathrm{~cm}$ from floor above scan 3 & 0.230 \\
$9 \mathrm{~cm}$ from floor above scan 1 & 0.396 \\
$9 \mathrm{~cm}$ from floor above scan 2 & 0.405 \\
$9 \mathrm{~cm}$ from floor above scan 3 & 0.405 \\
$1.3 \mathrm{~m}$ from bottom, 9 cm from side, above scan 3 & 0.150 \\
$1.3 \mathrm{~m}$ from bottom, 69 cm from side, above scan 3 & 0.162 \\
\hline
\end{tabular}

